\title{
BMJ Open Associations between work satisfaction, engagement and 7-day patient mortality: a cross-sectional survey
}

\author{
Kirsten Brubakk (D) , ${ }^{1}$ Martin Veel Svendsen, ${ }^{2}$ Dag Hofoss, ${ }^{3}$ Tonya Moen Hansen, ${ }^{4}$ \\ paul Barach (D) , ${ }^{5}$ Ole Tjomsland ${ }^{6}$
}

To cite: Brubakk K,

Svendsen MV, Hofoss D, et al. Associations between work satisfaction, engagement and 7-day patient mortality: a crosssectional survey. BMJ Open 2019:9:e031704. doi:10.1136/ bmjopen-2019-031704

- Prepublication history for this paper is available online. To view these files, please visit the journal online (http://dx.doi. org/10.1136/bmjopen-2019031704).

Received 16 May 2019 Revised 29 0ctober 2019 Accepted 05 November 2019

Check for updates

(c) Author(s) (or their employer(s)) 2019. Re-use permitted under CC BY-NC. No commercial re-use. See rights and permissions. Published by BMJ.

${ }^{1}$ Department of Human Resources, Helse Sør-Øst RHF, Hamar, Norway

${ }^{2}$ Department of Occupational and Environmental Medicine, Sykehuset Telemark HF, Skien, Norway

${ }^{3}$ Department of Postgraduate Studies, Lovisenberg Diaconal University College, Oslo, Norway ${ }^{4}$ Department of Health Services Research, Folkehelseinstituttet, Oslo, Norway

${ }^{5}$ Pediatrics, Wayne State University, Detroit, Michigan, USA

${ }^{6}$ Department of Health, Helse Sør-Øst RHF, Hamar, Norway

Correspondence to Kirsten Brubakk; kirsten.brubakk@helse-sorost. no

\section{ABSTRACT}

Objective This study examines the association between profession-specific work environments and the 7-day mortality of patients admitted to these units with acute myocardial infarction (AMI), stroke and hip fracture. Design A cross-sectional study combining patient mortality data extracted from the South-Eastern Norway Health Region, and the work environment scores at the hospital ward levels. A case-mix adjustment model was developed for the comparison between hospital wards. Setting Fifty-six patient wards in 20 hospitals administered by the South-Eastern Norway Regional Health Authority.

Participants In total, 46026 patients admitted to hospitals with AMI, stroke and hip fracture, and supported by 8800 survey responses from physicians, nurses and managers over a 3-year period (2010-2012).

Primary and secondary outcome measures The primary outcome measures were the associations between the relative mortality rate for patients admitted with AMI, stroke and hip fractures and the profession-specific (ie, nurses, physicians, middle managers) mean scores on the 19 organisational factors in a validated cross sectional, staff survey conducted annually in Norway. The secondary outcome measures were the mean scores with SD on the organisational factors in the staff survey reported by each profession.

Results The Nurse workload (beta 0.019 (95\% Cl0.009$0.028)$ ) and middle manager engagement (beta 0.024 (95\% Cl0.010-0.037)) levels were associated with a case-mix adjusted 7-day patient mortality rates. There was no significant association between physician work environment scores and patient mortality rates.

Conclusion 7-day mortality rates in hospital wards were negatively correlated with the nurse workload and manager engagement levels. A deeper understanding of the relationships between patient outcomes, organisational structure and their underlying cultural barriers is needed because they may provide a better understanding of the harm and death risks for patients due to organisational characteristics.

\section{INTRODUCTION}

Hospitals are complex social-cultural organisations defined by their complexity of operations, uncertainty and interdependency. ${ }^{1} \mathrm{~A}$ strong linkage between the organisation of

\section{Strengths and limitations of this study}

This is the first study, to our knowledge, combining profession-specific work place survey data with patient mortality data correlated with the hospital ward levels.

- This study is strengthened by the use of wardspecific level data as hospital data can mask interward differences.

- A case-mix adjustment model was developed for the comparison between hospital wards but not for the disease severity, thus it is hard to distinguish between patients who might die from the severity of their illness and less severe cases, for whom the lack of high-quality care ultimately may have reduced their chances of survival.

- Although the study included hospitals providing healthcare services to more than half of the Norwegian population, the number of wards is too small to allow the use of complex multivariate analyses.

care and patient outcomes has been found in several studies. ${ }^{23}$ Complex organisations rely on authentic inputs and interactions while they deliver an array of clinical services. In these settings, it can be hard to determine the proximal causes of an adverse patient event such as a cardiac arrest or a medication error. ${ }^{4} 5$ Numerous initiatives have been promoted to enhance the quality of the patient's journey when in hospital, and yet at least one in ten patients still experiences adverse events. ${ }^{6}$ High-reliability organisational theory posits that organisational features including psychological safety, ${ }^{7}$ leadership involvement, ${ }^{8}$ team based care, ${ }^{9}$ trusting support ${ }^{10}$ and a relentless culture of quality measurement are needed to sustain reliable improvements in care. ${ }^{11}$

The impact of organisational culture on quality, reporting of data and safety in nonmedical organisations is well documented. ${ }^{12-15}$ Monitoring staff perceptions of their work environment and their organisational culture 
is used by managers to discover what is deemed meaningful and makes organisational sense to employees. ${ }^{16}{ }^{17}$ Leggat et $a l^{18}$ have consistently demonstrated that a reported positive relationship between high-performance workplaces and organisational outcome also applies to patient outcomes in healthcare organisations. ${ }^{19}$

Systems science and human factors engineering posit that focusing on the workflow and environment, and the organisational culture can reduce work hazards and enable safer outcomes. ${ }^{20} 21$

Our hypothesis was that there is an association between the work environment and patient mortality, and that this association is profession-specific for nurses, physicians and middle managers. The secondary objective of this study was to examine the associations between professionspecific work environments and the 7-day mortality of patients admitted with one of three diagnoses: acute myocardial infarction (AMI), stroke and hip fracture.

\section{METHODS}

The survey population was drawn from one healthcare service provider, the South-Eastern Regional Health Authority (HSO), which is responsible for delivering healthcare services to approximately 3 million peoplemore than half of the population in Norway. The patient outcome data were derived from a national database (Norwegian Patient Register) for all patients admitted with AMI, stroke and hip fracture in 20 hospitals in Norway.

\section{The Work Environment Survey}

Staff in all hospitals administered by the HSO in Norway were invited to participate in a web-based work environment questionnaire based on the General Nordic Questionnaire for Psychological and Social Factors at Work (QPSnordic), that was adapted for healthcare. ${ }^{22}$ More than 75000 are employed in HSO, and all staff employed for more than 3 months in the hospital were eligible for participation. Nearly 50000 questionnaires were distributed in each of the studied years $(2010,2011,2012)$. The data was collected electronically. To secure anonymity of the participants, only data from wards with more than five responders were processed.

The survey was designed to assess the local hospital work environment and distinguish the differences between hospital wards. The questionnaire has 57 items, measuring the work environment along 19 dimensions (table 1). The survey was supplemented with questions addressing the factor patient safety culture as an important aspect of the healthcare work environment. The safety culture questions were adapted from the Norwegian validated version of the Safety Attitude Questionnaire. ${ }^{23}$ The response alternatives are presented on a 5-point Likert scale (for some items 'Strongly disagree', 'Disagree', 'Neither disagree nor agree', 'Agree', 'Strongly agree' or, where appropriate, 'Never/very seldom', 'Seldom', 'Sometimes', 'Quite often', 'Very often/always'). The categories were assigned the values 0-25-50-75-100, assuming an equal distance between scores. ${ }^{24}$ The value zero reflects the highest burden/least favourable conditions and the score 100 means the most positive rating (ie, is coping/satisfied). The coding of negatively worded items was reversed to ensure that the higher code values always indicate a more positive response. The score on each dimension was calculated as the mean of the score on each item included in the dimension. For each of the 56 wards in the study, the mean work environment scores were calculated. The individual responses with missing data were excluded from the analysis. A report with the mean average scores on each item and factor in the survey for each ward was produced and made public. Nurses in HSO are assigned to work on one designated hospital ward and the nurse responses were attributed to the specific ward; however, physicians and middle managers cover several wards or units. We measured the perceptions about the work environments where the physicians and middle managers work (entire clinical departments).

We defined the work system to include the persons, organisation, tools and technologies, tasks and their work environment. ${ }^{25}$ Work environment is the physical and organisational culture under which healthcare professionals perform their tasks. Patient safety culture is a component of organisational culture and has been shown to be associated with patient outcomes. ${ }^{26}$

The definitions and measurements of culture vary. For this study, we defined organisational culture as the behaviours that emerge based on shared values, beliefs, assumptions and norms. ${ }^{12} 1327$ Previous research has demonstrated more variation in culture assessments between different clinical wards within the same hospital than between the hospitals. ${ }^{28}$ We used the ward level as our level of outcomes, as previous studies have shown that data aggregated at the hospital level may mask the hospital unit's differences. ${ }^{29}$

\section{Patient Outcome Data}

The Norwegian Institute of Public Health (FHI) reports annually hospital survival probabilities for patients diagnosed with AMI, stroke, hip fracture and hospital-wide survival rate quality indicators for Norwegian hospitals. ${ }^{30}$ The mortality rates are estimated based on all-cause deaths, tracking patients with their unique Norwegian Personal Identification Number. The mortality rates were risk-adjusted for age, gender and the Charlson Comorbidity Index scores based on the patients' hospital admissions during the 3 years prior to their hospital admission, type of stroke (cerebral haemorrhage/cerebral infarction) and the total number of hospitalisations during the previous 2 years. In the event where a patient admission involved more than one hospital, the patient mortality probability was split between the two hospitals according to the time the patient spent at each hospital in order to reduce potential bias. The management and analysis methods of the Norwegian survival data are described in great detail by Hassani et al. ${ }^{31}{ }^{32}$ This study 
Table 1 Work environment factors and survey items

\begin{tabular}{ll} 
Domain scale & Items \\
\hline Goals & The unit goals are well known to all employees. \\
& I know how I can contribute to the unit to reach its goals. \\
& We regularly evaluate our achievements according to our goals.
\end{tabular}

Improvement

In my unit, we do well in reporting and follow-up on adverse events.

It is safe to report adverse events in my/this unit.

We openly discuss adverse events and learn from them.

In this unit, we encourage each other to think of ways to do things better.

Quality

In my unit different professions collaborate well.

We work efficiently in my unit.

In my unit high quality is maintained.

Patient centred

In my unit, we listen to the views of patients/clients.

In my unit, we are available to patients/clients.

In my unit, sufficient information is given to patients/clients.

\begin{tabular}{|c|c|}
\hline Respect & $\begin{array}{l}\text { In my unit, we respect patients/clients cultural background and religion. } \\
\text { In my unit, we comply to keep appointments made. } \\
\text { In my unit, we communicate clearly and in an understandable way. }\end{array}$ \\
\hline Motivation & $\begin{array}{l}\text { Is your work challenging in a positive way. } \\
\text { My work tasks engage me. } \\
\text { The work is so interesting in itself that it is strongly motivating. }\end{array}$ \\
\hline Engagement & $\begin{array}{l}\text { Do you look forward going to work. } \\
\text { How often does dissatisfaction with your work make you want to change employer. } \\
\text { Overall, how satisfied are you with the work you do now. }\end{array}$ \\
\hline Commitment & $\begin{array}{l}\text { To my friends, I praise this organisation as a great place to work. } \\
\text { This organisation inspires me to give my very best job performance. } \\
\text { I am proud of my workplace. }\end{array}$ \\
\hline Personal development & $\begin{array}{l}\text { I can develop professionally through my work. } \\
\text { I get sufficient training and advice to do a good job. } \\
\text { Is your work organised in a way that lets you improve your abilities? } \\
\text { Do you get feedback about the quality of the work you do? }\end{array}$ \\
\hline Empowerment & $\begin{array}{l}\text { Are you encouraged to participate in decision making? } \\
\text { Are you encouraged to speak up when you have a different opinion? }\end{array}$ \\
\hline Role expectations & $\begin{array}{l}\text { Do you know what your responsibilities are? } \\
\text { Do you know what is expected of you at work? }\end{array}$ \\
\hline Social climate & $\begin{array}{l}\text { Is the social climate in your unit characterised by a team spirit? } \\
\text { If needed, can you get support and help from your coworkers? } \\
\text { Do you perceive good collaboration in your unit? } \\
\text { Have you observed anyone being harassed or bullied at your workplace during the } \\
\text { last } 6 \text { months? } \\
\text { Have you noticed disruptive conflicts in your unit? } \\
\text { When conflicts occur, are they handled in a professional manner? }\end{array}$ \\
\hline Workload & $\begin{array}{l}\text { Is the physical load of your work too burdensome? } \\
\text { Is your work pace challenging? } \\
\text { Is your workload challenging? } \\
\text { Do you perform work tasks for which you need more training? }\end{array}$ \\
\hline Autonomy & $\begin{array}{l}\text { Can you influence the amount of work assigned to you? } \\
\text { Can you set your own work pace? }\end{array}$ \\
\hline Role conflicts & $\begin{array}{l}\text { Do you have to perform procedures which you feel should be done differently? } \\
\text { Are you given assignments without adequate resources to complete them? } \\
\text { Do you receive incompatible requests? }\end{array}$ \\
\hline Sick leave & Issues at work have contributed to my sick leaves during the last 12 months. \\
\hline
\end{tabular}

Continued 
Table 1 Continued

\begin{tabular}{ll}
\hline Domain scale & Items \\
\hline Leadership & My immediate superior is available to me when I need it. \\
& My immediate superior does an excellent job of giving us information about what \\
& goes on in our organisation. \\
& My immediate superior makes clear performance demands. \\
& My immediate superior adheres to what we have agreed on. \\
& If I were subjected to violence or threats, I could count on the support of my \\
& immediate superior. \\
& If I were sick for a more extended period, I could count on the support of my \\
& immediate superior. \\
Patient safety culture & I would feel safe if I was a patient here. \\
& Adverse medical events are appropriately handled here. \\
\hline
\end{tabular}

used risk-adjusted patient data from the FHI for patients admitted to hospitals with AMI, stroke and hip fracture.

The 7-day mortality rate was chosen to study the possible associations between the work environment and mortality for high-risk patients in hospital. A more extended observation period (such as 30 days), might confound the findings and include mortality unrelated to hospital characteristics, such as variations in post discharge care at local nursing homes and home healthcare services. Importantly, the ward mortality rates were calculated for the patients with the included diagnosis only, and not combined with the mortality of patients with other diagnoses, even if they were cared for on the same wards.

The relative mortality rates were defined as the deviation of the hospital unit's mortality rates from the mean mortality rates for the specific diagnosis groups, and then they were divided by the mean mortality rates for the specific diagnosis group. This relative mortality rate can be compared across all three diagnostic groups and allows for pooling of all hospital ward data. The formula we used is as follows:

$$
{\text { Relative morality } \text { rate }_{\text {unit }}=\frac{\text { Mean morality rate }}{\text { patient group }}-\text { Morality rate }_{\text {unit }}}_{\text {Mean morality rate }}^{\text {patient group }}
$$

The diagnosis-specific outcomes were aggregated over a 3-year period $(2010,2011,2012)$ to ensure adequate statistical power.

\section{Selection of hospitals}

All 20 public hospitals in HSO providing acute care were included, with 17 hospitals that treated all three patient diagnoses included in this study, while three hospitals treated only one or two of the three included patient subgroups, for a total of 56 wards. The hospitals varied in size and geographical catchment areas, but had comparable organisational structures and policies, with specially designated patient wards caring for the three subgroups of patients. Patients admitted with a cerebral stroke were treated in stroke units according to national guidelines, ${ }^{33}$ whereas patients with a hip fracture were postoperatively cared for on orthopaedic wards. Patients with AMI were subjected to a prehospital triage such that patients with suspected ST-elevation myocardial (STEMI)infarction were transported directly to PCI centres, whereas, patients with non-STEMI infarction were admitted to cardiac units at each of the respective HSO hospitals.

The ward level data on the work environment scores was made available from HSO and the patient mortality rates were made available from the FHI for the 3-year period $(2010,2011,2012)$ and were combined using ward names as an identifier.

\section{Statistical analyses}

The descriptive data on number of patients treated and survey responses were given as medians and the range due to the non-normal distribution. Normality was tested by the non-parametric Kolmogorov-Smirnov test. ${ }^{34}$ The associations between the profession-specific work environments and adjusted patient mortality rates at a specific ward level were analysed using a linear regression model that was adjusted for diagnosis and the annual number of treatments.

The effects of the different work environmental factors were analysed and reported separately, as the limited number of wards studied $(n=56)$ prohibited including all explanatory variables in one single multivariable predictive model. A backward conditional regression analysis was performed by including all the significant work environmental factors from the initial separate analysis (Nurses: patient centred, respect, motivation, engagement, commitment, role expectations, workload, autonomy, role conflicts, sick leave, leadership, patient safety climate; Physicians: none; Managers: quality, motivation, engagement, commitment, personal development, empowerment, social climate, workload, role conflicts). The level for the removal of variables was set to $\mathrm{p}>0.05$. Both the variables available for the backward regression and the final models were evaluated against our hypothesis and prior research and was found to be plausible. In addition alternative approaches as manually built models did not identify better performing models. The work environment effects for physicians, nurses and middle managers were analysed separately to assess how patient mortality was associated with the work environment for the three professions. The statistical significance level was set at 0.05 , and the $95 \%$ CIs are presented below. 
Table 2 Description of survey Respondents by age and profession

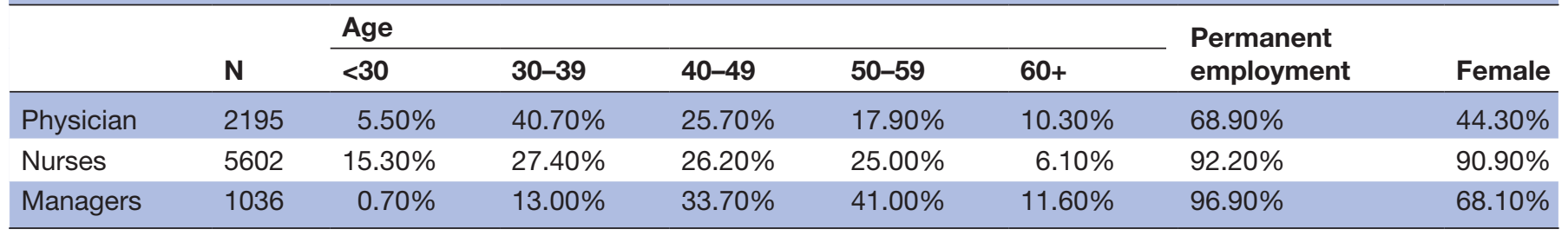

All outcomes and statistical analyses were carried out using the IBM SPSS statistical package V.21.

\section{Patient and public involvement}

The study protocol and results of this study have been presented to the regional patient representative committee who supported the study design and its relevance.

\section{RESULTS}

The web-based work environment and safety culture data were collected from 2010 to 2012. Nearly 50000 questionnaires were distributed annually. The response rates for 2010, 2011 and 2012, were $72 \%, 77 \%$ and $75 \%$, respectively. The background information such as gender, age and profession was stated voluntarily. Seventy-eight percent of the respondents defined their occupation. In total, 5602 responses from nurses, 2195 from physicians and 1036 from middle managers were included in the analysis (table 2).

All emergency patients admitted with AMI, stroke and hip fracture were included. Diagnosis-specific mortality rates were calculated for all adult patients (age $>18$ ) with the corresponding diagnoses as follows: 17734 patients admitted with first time AMI (ICD-10 I21.x), 14442 cerebral stroke patients (ICD-10 I61.63.64), and 13850 patients admitted over the age of 65 with a hip fracture (ICD-10 S72.0-2). The average length of hospital stay for the patients included in the study was 8.1 days. The 7-day mortality rates varied from $2.8 \%-7.7 \%$. The mean Charlson Comorbidity Index score was 1.5 (table 3 ).

The median number of treatments for the 56 wards that participated in this study, (patients within the diagnosis codes included) were 214, with a range varying from 36 to 1242 . The median number of work environment survey responses per ward included in the analysis was 87 (range 26-296) for nurses, 32 (range 5-157) for physicians and 15 (range 5-47) for managers.

Hospital staff rated their work environment positively on the $0-100$ scale (100 indicating the most favourable condition): the mean scores for nurses, physicians and middle managers were 70.5, 67.2 and 76.3, respectively. The middle managers reported higher scores than physicians and nurses on all but three of the 19 organisational factors, while the nurses scored lower than managers and physicians on nine of the 19 factors. The mean scores and SD for each factor are presented by profession in table 4 .
Table 5 shows that several organisational factors were significantly associated with increased patient mortality probability. The backward regression model demonstrated that a higher perceived workload by nurses was significantly associated with increased patient mortality: beta $=0.019$ (95\% CI0.009, 0.028). Nurses: workload $\mathrm{p}<0.001$, respect $\mathrm{p}=0.002$, patient safety culture $\mathrm{p}=0.003$, role conflicts $p=0.004$, patient centred $p=0.005$, engagement $\mathrm{p}=0.005$, autonomy $\mathrm{p}=0.007$, sick leave $\mathrm{p}=0.007$, commitment $\mathrm{p}=0.009$, motivation $\mathrm{p}=0.022$, role expectation $\mathrm{p}=0.031$, leadership $\mathrm{p}=0.045$. For middle managers, engagement was significantly associated with 7-day mortality: beta $=0.024$ (95\% CI $0.010,0.037)$. Middle managers: engagement $\mathrm{p}=0.001$, personal development $\mathrm{p}=0.001$, motivation $\mathrm{p}=0.002$, social climate $\mathrm{p}=0.005$, workload $\mathrm{p}=0.006$, commitment $\mathrm{p}=0.010$, role conflict $\mathrm{p}=0.010$. No significant association was found between the physician reported work environment scores and patient mortality.

\section{DISCUSSION}

We found a strong correlation between organisational work environment and 7-day patient mortality. This study extends findings in the literature demonstrating that the work environment at the 20 South-Eastern Norway Health Region Hospitals were significantly related to their reported 7-day mortality for patients admitted with AMI, stroke and hip fractures. We observed a significant increase in patient mortality in hospital units where nurses reported excessive workload and middle managers reported a lack of professional and organisational engagement. No such associations were found between physician reported work environment and patient mortality.

Hospital staff scored their work environment positive (over 70) on a $0-100$ scale (100 being the most favourable), consistent with the general satisfaction reported by Norwegian employees who report higher job satisfaction than employees in other countries. ${ }^{35}$ However, there were profession-specific differences that may have contributed to the observed variation in the patient outcomes across the 56 hospital wards. Overall, the middle managers scored higher than physicians and nurses, and nurses scored lowest on more organisational factors than managers and physicians.

Whereas nurses typically worked on one hospital ward, physicians and middle managers usually worked and saw patients on several clinical units, and the assessment of 
Table 3 Description of patients and clinical outcomes

\begin{tabular}{lllc}
\hline & $\begin{array}{l}\text { Acute myocardial infarction } \\
\text { (first time) }\end{array}$ & Stroke & $\begin{array}{l}\text { Hip fracture } \\
(>65 \text { years) }\end{array}$ \\
\hline Number of patients & 17734 & 14442 & 13850 \\
\hline Number of admissions & 17734 & 15235 & 14427 \\
\hline Death within 7 days, unadjusted & $1234(7.0 \%)$ & $1180(7.7 \%)$ & $399(2.8 \%)$ \\
\hline Death within 30 days, unadjusted & $2030(11.4 \%)$ & $2167(14.2 \%)$ & $1314(9.1 \%)$ \\
\hline Mean length of stay (days) & 7.0 & 10.2 & 7.2 \\
\hline Treated in two or more hospitals & $10412(58.7 \%)$ & $1915(12.6 \%)$ & $1252(8.7 \%)$ \\
\hline Gender, female & $6785(38.3 \%)$ & $7297(47.9 \%)$ & $10297(71.4 \%)$ \\
\hline Age, mean & 71.0 & 74.6 & 83.4 \\
\hline 0-17 years & $0(0.0 \%)$ & $0(0.0 \%)$ & $0(0.0 \%)$ \\
\hline $18-49$ years & $1411(8.0 \%)$ & $777(5.1 \%)$ & $0(0.0 \%)$ \\
\hline $50-75$ years & $8854(49.9 \%)$ & $6234(40.9 \%)$ & $2549(17.7 \%)$ \\
\hline 75 years & $7469(42.1 \%)$ & $8224(54.0 \%)$ & $11878(82.3 \%)$ \\
\hline Number of previous hospitalisation during last & 5.8 & 5.8 & 5.9 \\
2 years, mean & & $2432(16.0 \%)$ & $1652(11.5 \%)$ \\
\hline 0 & $3786(21.3 \%)$ & $2181(14.3 \%)$ & $2069(14.3 \%)$ \\
\hline 1 & $2799(15.8 \%)$ & $1914(12.6 \%)$ & $2008(13.9 \%)$ \\
\hline 2 & $2189(12.3 \%)$ & $3922(25.7 \%)$ & $4142(28.7 \%)$ \\
\hline $3-5$ & $4130(23.3 \%)$ & $4786(31.4 \%)$ & $4556(31.6 \%)$ \\
\hline $6+$ & $4830(27.2 \%)$ & 1.3 & 1.8 \\
\hline Charlson Comorbidity Index, mean & 1.5 & $8131(53.4 \%)$ & $5914(41.0 \%)$ \\
\hline p points & $8827(49.8 \%)$ & $1658(10.9 \%)$ & $1404(9.7 \%)$ \\
\hline points & $1646(9.3 \%)$ & $2638(17.3 \%)$ & $3493(24.2 \%)$ \\
\hline points + points & $3096(17.5 \%)$ & $2808(18.4 \%)$ & $3616(25.1 \%)$ \\
\hline
\end{tabular}

their work environment should be interpreted accordingly. We stress that it is not the physician or manager perceptions of the patient ward that are being measured, but the explicit perceptions about their work environments where physicians and middle managers work (entire clinical departments) supporting these patient wards.

Twelve of the 19 organisational environmental factors scored by nurses were significantly associated with 7-day patient mortality suggesting that the reported nursing workload may be underappreciated as an important driver for nurse satisfaction. ${ }^{36}$ The workload was the most prominent and derived from survey items such as: 'Is the physical load of your work too heavy?', Is your workload challenging?' and 'Do you perform work tasks for which you need more training?' These survey items describe the nurses' perceptions about their degree of control over the daily assigned tasks. Our findings reinforce previous studies suggesting that reducing the nurse workload may increase nurse satisfaction and decrease patient mortality. ${ }^{37-43}$

Managers play a critical role, as frontline leaders, in nurturing a psychologically safe culture by setting the norms for speaking up, and promoting shared meanings and practices. ${ }^{44-46}$ The middle managerial roles, situated between the senior hospital management and frontline workers, offers a unique vantage point to assess the maturity of the culture as they implement and oversee strategies and work policies. At the same time, middle managers are responsible for bringing staff concerns and needs back to senior management for consideration and action. Managers can contribute to organisational change by capitalising on this position, ${ }^{47}$ as management involvement and engagement have been documented as a positive influence on care delivery systems. ${ }^{8}{ }^{449}$ At the same time, top-management and hospital boards engagement in patient safety initiatives can enhance the middle managers' support for a safety culture that can affect patient mortality. ${ }^{50}$

As noted above, we did not find a correlation between patient mortality and physicians' perception of their work environment. The interpretation may not necessarily mean that physician work environment is unrelated to patient outcomes. We think this may be the result of physicians' sense of autonomy, ${ }^{51}$ and their responsibility covering patients on multiple departments and service lines simultaneously, and this might affect their responses. Nurses define their work environment in more 
Table 4 Organisationalfactor score averages by professions in 56 hospital units

\begin{tabular}{|c|c|c|c|c|c|c|}
\hline \multirow[b]{2}{*}{ Measures } & \multicolumn{2}{|l|}{ Nurse } & \multicolumn{2}{|c|}{ Physician } & \multicolumn{2}{|c|}{ Manager } \\
\hline & Mean & SD & Mean & SD & Mean & SD \\
\hline Goals & 62 & 7 & 63 & 9 & 72 & 8 \\
\hline Improvement & 65 & 6 & 69 & 7 & 76 & 6 \\
\hline $\begin{array}{l}\text { Quality and } \\
\text { efficiency }\end{array}$ & 77 & 6 & 77 & 8 & 78 & 8 \\
\hline Patient-centred & 76 & 6 & 76 & 6 & 77 & 6 \\
\hline Respect for patients & 74 & 4 & 74 & 6 & 76 & 6 \\
\hline Motivation & 75 & 5 & 78 & 7 & 82 & 5 \\
\hline Engagement & 76 & 7 & 75 & 8 & 81 & 7 \\
\hline Commitment & 75 & 9 & 71 & 10 & 81 & 7 \\
\hline $\begin{array}{l}\text { Personal } \\
\text { development }\end{array}$ & 62 & 7 & 63 & 8 & 70 & 9 \\
\hline Empowerment & 55 & 6 & 60 & 9 & 74 & 9 \\
\hline Role expectations & 89 & 3 & 85 & 6 & 88 & 5 \\
\hline Social interactions & 83 & 6 & 79 & 8 & 81 & 7 \\
\hline $\begin{array}{l}\text { Conflicts and } \\
\text { bullying }\end{array}$ & 75 & 5 & 73 & 9 & 81 & 7 \\
\hline Workload & 52 & 9 & 54 & 7 & 62 & 7 \\
\hline Autonomy & 39 & 7 & 38 & 7 & 46 & 9 \\
\hline Role conflicts & 68 & 5 & 66 & 7 & 64 & 9 \\
\hline Sick leave & 86 & 6 & 93 & 8 & 94 & 8 \\
\hline Leadership & 74 & 9 & 75 & 9 & 77 & 12 \\
\hline $\begin{array}{l}\text { Patient safety } \\
\text { culture }\end{array}$ & 78 & 8 & 85 & 7 & 90 & 7 \\
\hline
\end{tabular}

straightforward terms. Their work is generally restricted to one patient ward, and they will have this ward in mind when responding to work surveys. Nurses report to, and are assigned tasks by, a supervisor on a daily basis; the same cannot be said for physicians who have much autonomy about when and where their care activities take place. This structural difference can lead to a physician-as-manager philosophy and a nurse-as-employee philosophy in many healthcare organisations and contribute to variation seen when assessing the impact of clinical interventions on different providers. Previous research has identified differences in culture and work styles within hospitals, and much of this variance was found to be located at the ward and microsystem levels. ${ }^{29}$ The responses from physicians working on several hospital wards may attenuate these interward differences, as their answers are based on their 'average experiences' from several clinical environments. This might explain the physician lack of significant association by hospital ward.

We focused on mortality rates as our dependent variable as mortality is well-defined, easily measured, considered useful for estimating the effect of hospital care ${ }^{3252}$ and 'it matters a lot to patients'. ${ }^{53}$ Patient mortality rates in Norwegian hospitals and the variation between hospitals is lower than in other OECD (Organisation for Economic Co-operation and developement) countries. ${ }^{54}$ However, some Norwegian hospitals have mortality rates significantly higher than the national average. Although a significant part of the variation observed in hospital mortality can be explained by differences in the case-mix and to random variation, it has been suggested that as much as $30 \%-60 \%$ of this variation can be attributed to differences in the practices and quality of patient care.$^{55}$ Some hospitals have structures and processes that minimise avoidable patient deaths better than others. ${ }^{56}$ Studying these high-performing hospitals can be valuable as they provide deeper insights about which factors are most important for organisational success and reliability. ${ }^{57}$

Our study have several limitations. First, the lack of available, detailed data on the severity of the patient's illnesses at the time of their hospital admission. Our data was case-mix adjusted for age, gender, comorbidity and the number of previous hospitalisations 2 years before the present admission, but not, for the disease severity of each diagnosis. Accordingly, it is challenging to distinguish between patients who may have died from the severity of their illness and less severe cases, for whom the lack of high-quality care ultimately may have reduced their chances of survival.

Second, the study design did not allow the linking of nurse, physician and middle manager' care culture evaluation to the survival of the individual patients under their care. That is, we were only able to relate the average staff evaluations to the average patient mortality for each hospital unit. However, we addressed this by using a diagnosis-specific mortality rate that allowed us to link the work environmental perceptions to the hospital wards where the patients were treated for their primary diagnosis. This afforded us the opportunity to dig deeper into our study dataset to examine the robust links between the work environment and patient outcomes.

Third, the previous safety culture literature may also be subject to publication bias. ${ }^{58}$ Few randomised controlled studies exist to demonstrate the causal relationships between organisational culture and clinical outcomes. Thus, our findings are important and have practical implications. Also, the culture evaluation surveys are susceptible to response bias at both the individual and ward respondent levels, but our response rate of $70 \%-75 \%$ compares favourably with those of similar studies. ${ }^{59} \mathrm{We}$ believe that one should consider other methodologies (qualitative/ethnographic) as useful tools for a deeper exploration of the informal work cultures of the high and low performing wards in our study and how they might affect the success of these hospital wards. ${ }^{6061}$

Because all the analyses are conducted at the hospital ward level, our sample of 56 wards is relatively small to detect statistical significance, making the size and direction of the correlation coefficients more informative in this context. Although the included hospitals represent nearly half of all Norwegian hospital beds, Norway is a small country and the limited number of units prevents complex multivariate analyses. This could mean that the variables that could have explained the mortality variation could not be controlled 


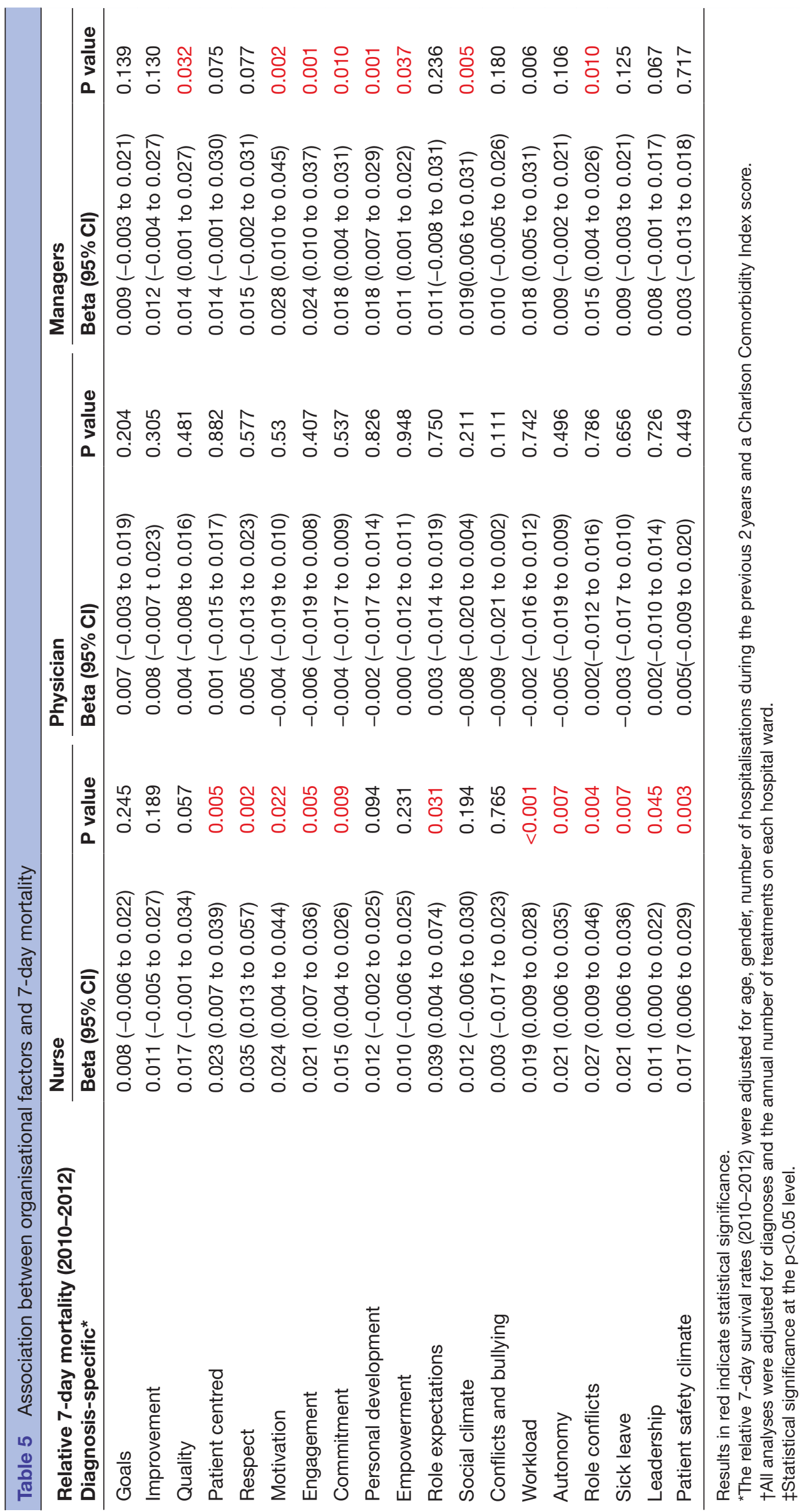


for. We cannot rule out the possibility that the associations we observed may therefore be non-causal.

Finally, our study reflects the context and distinct constraints of the Norwegian healthcare delivery systems, which may be different from other healthcare systems. Norwegian employees generally perceive their work environment as more positive than staff in other countries, ${ }^{35}$ and patient survival is relatively high. ${ }^{54}$ The study, however, probably carries relevance for the population as a whole, and has strong external generalisability to other countries, because it stems from a large and diverse sample of hospitals.

\section{CONCLUSIONS}

Patients fare better in hospitals in which employees declare a supportive and nurturing place to work. Our data suggest that if nurses feel supported, and managers feel engaged in their work, these organisational features of care delivery systems can affect patient hospital mortality. A deeper understanding of these cultural and organisational influences, and how they can increase the performance toward achieving the overall organisation goals, is critical to developing meaningful interventions to improve patient outcomes. Assessment of these organisational and cultural metrics might be quite useful in monitoring the safety of hospitals and supporting hospital quality improvement efforts.

Acknowledgements The authors thank professors Brian Jarman and Richard Frankel for their thoughtful review and suggestions for improving the manuscript.

Contributors KB developed the idea for the study, interpreted results, drafted and revised manuscript; MVS conducted analysis, drafted the results, contributed to manuscript revisions; DH contributed to result interpretation and manuscript drafting and revisions; TMH contributed to obtaining patient data and manuscript revisions; PB contributed to manuscript development and revisions; OT contributed to interpretation of results, manuscript development and revisions.

Funding The authors have not declared a specific grant for this research from any funding agency in the public, commercial or not-for-profit sectors.

Competing interests None declared.

Patient consent for publication Not required.

Ethics approval The study was approved by the Medical and Health Research Ethics Committee (REC) in South Eastern Norway with waiver of informed consent, since all data used in the study were anonymous. (Case number 2011/2345 D).

Provenance and peer review Not commissioned; externally peer reviewed.

Data availability statement All data relevant to the study are included in the article or uploaded as supplementary information.

Open access This is an open access article distributed in accordance with the Creative Commons Attribution Non Commercial (CC BY-NC 4.0) license, which permits others to distribute, remix, adapt, build upon this work non-commercially, and license their derivative works on different terms, provided the original work is properly cited, appropriate credit is given, any changes made indicated, and the use is non-commercial. See: http://creativecommons.org/licenses/by-nc/4.0/.

\section{ORCID iDs}

Kirsten Brubakk http://orcid.org/0000-0002-0618-5873

paul Barach http://orcid.org/0000-0002-7906-698X

\section{REFERENCES}

1 Snowden DJ, Boone ME. A leaders framework for decision MakingWise executive tailor their approach to fit the complexity of the circumstances they face. Harv Bus Rev 2007;85:68.
2 Mitchell PH, Shortell SM. Adverse outcomes and variations in organization of care delivery. Med Care 1997;35:NS19-32.

3 Kohn LT, Corrigan JM, Donaldson M. To err is human: building a safer health system. Washington, DC: National Academy Press, 1999.

4 Craig P, Dieppe P, Macintyre S, et al. Developing and evaluating complex interventions: the new medical Research Council guidance. BMJ 2008;337.

5 Cassin BR, Barach PR. Making sense of root cause analysis investigations of surgery-related adverse events. Surg Clin North Am 2012;92:101-15.

6 Soop M, Fryksmark U, Köster M, et al. The incidence of adverse events in Swedish hospitals: a retrospective medical record review study. Int J Qual Health Care 2009;21:285-91.

7 Rosenbaum L. Cursed by Knowledge - Building a Culture of Psychological Safety. N Engl J Med 2019;380:786-90.

8 Parand A, Dopson S, Renz A, et al. The role of hospital managers in quality and patient safety: a systematic review. BMJ Open 2014;4:e005055.

9 Salas E, Baker D, King H, et al. On teams, organizations, and safety: of Course... Jt Comm J Qual Patient Saf 2006;32:112-3.

10 Frankel RM, Tilden VP, Suchman A. Physicians' trust in one another. JAMA 2019;321:1345-6.

11 Lawton R, Taylor N, Clay-Williams R, et al. Positive deviance: a different approach to achieving patient safety. BMJ Qual Saf 2014;23:880-3.

12 Schein EH. Organizational culture and leadership. John Wiley \& Sons, 2010.

13 Bolman LG, Deal TE. Reframing organizations: Artistry, choice, and leadership. John Wiley \& Sons, 2003.

14 Barach P, Small SD. How the NHS can improve safety and learning: by learning free lessons from near misses. BMJ 2000;320.

15 Macrae C, Stewart K. Can we import improvements from industry to healthcare? BMJ 2019;26.

16 Hall LH, Johnson J, Watt I, et al. Healthcare staff wellbeing, burnout, and patient safety: a systematic review. PLoS One 2016;11:e0159015.

17 Barach P, Phelps G. Clinical sensemaking: a systematic approach to reduce the impact of normalised deviance in the medical profession. $J$ R Soc Med 2013;106:387-90.

18 Leggat SG, Bartram T, Casimir G, et al. Nurse perceptions of the quality of patient care: confirming the importance of empowerment and job satisfaction. Health Care Manage Rev 2010;35:355-64.

19 Braithwaite J, Herkes J, Ludlow K, et al. Association between organisational and workplace cultures, and patient outcomes: systematic review. BMJ Open 2017;7:e017708.

20 Karsh B-T, Holden RJ, Alper SJ, et al. A human factors engineering paradigm for patient safety: designing to support the performance of the healthcare professional. Qual Saf Health Care 2006;15(Suppl 1):i59-65.

21 Wahr JA, Prager RL, Abernathy JH, et al. Patient safety in the cardiac operating room: human factors and teamwork: a scientific statement from the American heart association. Circulation 2013;128:1139-69.

22 Wännström I, Peterson U, Åsberg M, et al. Psychometric properties of scales in the general Nordic questionnaire for psychological and social factors at work (QPS): confirmatory factor analysis and prediction of certified long-term sickness absence. Scand J Psychol 2009;50:231-44.

23 Deilkås ET, Hofoss D. Psychometric properties of the Norwegian version of the safety attitudes questionnaire (SAQ), generic version (short form 2006). BMC Health Serv Res 2008;8:191.

24 Huang DT, Clermont G, Kong L, et al. Intensive care unit safety culture and outcomes: a US multicenter study. Int J Qual Health Care 2010;22:151-61.

25 Carayon P, Schoofs Hundt A, Karsh B-T, et al. Work system design for patient safety: the SEIPS model. Qual Saf Health Care 2006;15(Suppl 1):i50-8.

26 Palmieri PA, Peterson LT, Pesta BJ, et al. Safety culture as a contemporary healthcare construct: theoretical review, research assessment, and translation to human resource management. strategic human resource management in health care. Emerald Group Publishing Limited, 2010: 97-133.

27 Brown A. Organizational culture: the key to effective leadership and organizational development. Leadership Org Development $J$ 1992;13:3-6.

28 Hudson DW, Berenholtz SM, Thomas EJ, et al. A safety culture primer for the critical care clinician: the role of culture in patient safety and quality improvement. Contemp Crit Care 2009;7:1-11.

29 Deilkås E, Hofoss D. Patient safety culture lives in departments and wards: multilevel partitioning of variance in patient safety culture. BMC Health Serv Res 2010;10:85. 
30 Helgeland JKD, Hassani S, Lindman AS. Overlevelse OG reinnleggelse ved norske sykehus for 2012. Oslo: Nasjonalt kunnskapssenter for helsetjeneaten, 2013.

31 Hassani S, Lindman AS, Kristoffersen DT, et al. 30-Day survival probabilities as a quality indicator for Norwegian hospitals: data management and analysis. PLoS One 2015;10:e0136547.

32 Kristoffersen DT, Helgeland J, Waage HP, et al. Survival curves to support quality improvement in hospitals with excess 30 -day mortality after acute myocardial infarction, cerebral stroke and hip fracture: a before-after study. BMJ Open 2015;5:e006741.

33 Helsedirektoratet. Nasjonale faglige retningslinjer for behandling OG rehabilitering ved hjerneslag. Oslo: Helsedirektoratet, 2017.

34 Berger VW, Zhou Y. Kolmogorov-smirnov test: overview. Wiley statsref: Statistics reference online, 2014.

35 Hanglberger D. Arbeitszufriedenheit Im internationalen Vergleich FFB-Diskussionspapier, 2011. http://hdl.handle.net/10419/67925

36 Weigl M, Stab N, Herms I, et al. The associations of supervisor support and work overload with burnout and depression: a crosssectional study in two nursing settings. J Adv Nurs 2016;72:1774-88.

37 McHugh MD, Rochman MF, Sloane DM, et al. Better nurse staffing and nurse work environments associated with increased survival of in-hospital cardiac arrest patients. Med Care 2016;54:74-80.

38 Faisy C, Davagnar C, Ladiray D, et al. Nurse workload and inexperienced medical staff members are associated with seasonal peaks in severe adverse events in the adult medical intensive care unit: a seven-year prospective study. Int J Nurs Stud 2016;62:60-70.

39 Aiken LH, Clarke SP, Sloane DM, et al. Hospital nurse staffing and patient mortality, nurse burnout, and job dissatisfaction. JAMA 2002;288:1987-93.

40 McHugh MD, Ma C. Hospital nursing and 30-day readmissions among Medicare patients with heart failure, acute myocardial infarction, and pneumonia. Med Care 2013;51:52-9.

41 Kane RL, Shamliyan TA, Mueller C, et al. The association of registered nurse staffing levels and patient outcomes: systematic review and meta-analysis. Med Care 2007;45:1195-204.

42 Carayon P, Gurses AP. Nursing workload and patient safety-a human factors engineering perspective. In: RG H, ed. Patient safety and quality: an evidence-based Handbook for nurses. Rockville (MD: Agency for Healthcare Research and Quality (US), 2008.

43 Tvedt C, Sjetne IS, Helgeland J, et al. An observational study: associations between nurse-reported Hospital characteristics and estimated 30-day survival probabilities. BMJ Qual Saf 2014;23:757-64.

44 West MA, Borrill C, Dawson J, et al. The link between the management of employees and patient mortality in acute hospitals. Int J Hum Resour Manag 2002;13:1299-310.
45 Edmondson A, Moingeon B. Learning, trust and organizational change. In: Organizational learning and the learning organization. SAGE Publishing, 1999: 157-75.

46 Rosenbaum L. Cursed by Knowledge-Building a culture of psychological safety: mass medical soc 2019.

47 Gutberg J, Berta W. Understanding middle managers' influence in implementing patient safety culture. BMC Health Serv Res 2017; 17:582

48 West M, Dawson J. Employee engagement and NHS performance: King's Fund. London, 2012.

49 Veronesi G, Kirkpatrick I, Altanlar A. Are public sector managers a "bureaucratic burden"? the case of english public hospitals. J Public Adm Res Theory 2019;29:193-209.

50 Conway J. Getting boards on board: engaging governing boards in quality and safety. Jt Comm J Qual Patient Saf 2008;34:214-20.

51 Amalberti R, Auroy Y, Berwick D, et al. Five system barriers to achieving ultrasafe health care. Ann Intern Med 2005;142:756-64.

52 Borzecki AM, Christiansen CL, Chew P, et al. Comparison of inhospital versus 30 -day mortality assessments for selected medical conditions. Med Care 2010;48:1117-21.

53 Krumholz HM, Wang Y, Mattera JA, et al. An administrative claims model suitable for profiling Hospital performance based on 30-day mortality rates among patients with an acute myocardial infarction. Circulation 2006;113:1683-92.

54 OECD. Health at a glance 2013: OECD indicators. OECD, 2013.

55 Cecil E, Wilkinson S, Bottle A, et al. National hospital mortality surveillance system: a descriptive analysis. BMJ Qual Saf 2018;27:974-81.

56 Tourangeau AE, Cranley LA, Jeffs L. Impact of nursing on hospital patient mortality: a focused review and related policy implications. Qual Saf Health Care 2006;15:4-8.

57 Taylor N, Clay-Williams R, Hogden E, et al. High performing hospitals: a qualitative systematic review of associated factors and practical strategies for improvement. BMC Health Serv Res 2015; $15: 244$

58 loannidis JPA, Munafò MR, Fusar-Poli P, et al. Publication and other reporting biases in cognitive sciences: detection, prevalence, and prevention. Trends Cogn Sci 2014;18:235-41.

59 Shanafelt TD, Mungo M, Schmitgen J, et al. Longitudinal study evaluating the association between physician burnout and changes in professional work effort. Mayo Clin Proc 2016;91:422-31.

60 Bognár A, Barach P, Johnson JK, et al. Errors and the burden of errors: attitudes, perceptions, and the culture of safety in pediatric cardiac surgical teams. Ann Thorac Surg 2008;85:1374-81.

61 Mohr J, Barach P. Understanding the design of health care organizations: the role of qualitative research methods. Environ Behav 2008;40:191-205. 